\title{
A BISECTION METHOD FOR THE TRAVELING SALESMAN PROBLEM
}

- The note deals with a new primal method for the traveling salesman problem. The fundamental step of the method is very similar to that of Netter [7] but some modifications with the idea of bisection cause the presented algorithm to be faster than Netter's algorithm.

1. Introduction. The traveling salesman problem (TSP) is stated as follows. Let $D_{d}=\langle X, U ; d\rangle$ be the digraph with arc weights, where $X$ is the set of vertices, $U \subseteq X \times X$, and $d$ is a real function, $d: U \rightarrow \boldsymbol{R}_{+} \cup\{0\}$. Let $|X|=n$. Then determine a minimum Hamiltonian circuit of the network $D_{d}$.

The TSP is one of the problems for which an efficient algorithm has not been presented yet (the efficiency in the sense of Edmonds, see [4]). This short note deals with a new method for the TSP.

2. The method. Let $t^{*}$ denote the length of a minimum Hamiltonian circuit of the network $D_{d}$. There exist some lower and upper bounds to $t^{*}$ and methods for examination of the inequality $t^{*} \leqslant t$ for any real number $t$. Let $t_{1}$ and $t_{\mathrm{u}}$ denote the lower and upper bounds, respectively, to the optimal solution of the TSP, i.e., $t_{1} \leqslant t^{*} \leqslant t_{u}$. Then the following is the representation of our proposed algorithm:

Step 1. $t \leftarrow t_{1}+0.5\left(t_{\mathrm{u}}-t_{1}\right)$.

Step 2. $t_{\mathrm{u}} \leftarrow t^{\prime}$ if $t^{*} \leqslant t$, and $t_{1} \leftarrow t$ otherwise, where $t^{\prime}\left(t^{*} \leqslant t^{\prime} \leqslant t\right)$ is the cost of the Hamiltonian circuit obtained as the result of examination of the inequality $t^{*} \leqslant t$.

Repeat steps 1 and 2 until a required accuracy is attained, i.e., until $t_{\mathrm{u}}-t_{1} \leqslant \varepsilon$, where $\varepsilon$ is a fixed small number.

The number of iterations of steps 1 and 2 for the TSP, with an integer function $d$ and integer variables $t_{1}, t_{\mathrm{u}}$ and $t$, is not greater than $\log _{2}\left(t_{\mathrm{u}}-t_{1}\right)$, where $t_{1}$ and $t_{\mathrm{u}}$ are the initial bounds to the optimal solution $t^{*}$.

The efficiency of the algorithm depends on the efficiencies attained at the following stages: 
(i) computation of an initial value of $t_{1}$;

(ii) computation of an initial value of $t_{\mathrm{u}}$;

(iii) examination of the inequality $t^{*} \leqslant t$.

As regards (i), the optimal solution of the assignment problem (AP) for the matrix $D=\left(d_{i j}\right)$ is the lower bound to the optimal solution of the TSP for the function $d([i, j])=d_{i j}(i, j=1,2, \ldots, n)$. A better lower bound can be obtained by Christofides' method [1], resulting in the order of difficulty of this stage of the algorithm being $n^{3}$.

With respect to stage (ii), the length of an arbitrary Hamiltonian circuit of the network $D_{d}$, particularly the length of the Hamiltonian circuit obtained by the nearest-city method, is the upper bound to the optimal solution of the TSP. At this stage, the order of difficulty is $n^{3}$.

In regard to (iii), the inequality $t^{*} \leqslant t$ can be examined by Netter's method [7]. Let us define, for a fixed number $t$ (step 2 of the algorithm), the network $D_{d, v}=\langle X, U ; d, v\rangle$ derived from the network $D_{d}$ and such that

$v: X \rightarrow \boldsymbol{R}_{-} \cup\{0\} \quad$ and $\quad \sum_{i=1}^{n} t_{i}=-t, \quad$ where $v(i)=t_{i}(i=1,2, \ldots, n)$.

Let the length of a circuit $\left[i_{1}, i_{2}, \ldots, i_{k}, i_{l}\right]$ in the network $D_{d, v}$ be defined as

$$
\sum_{j=1}^{k} d_{i_{j} i_{j+1}}+\sum_{j=1}^{k} t_{i_{j}}, \quad \text { where } i_{k+1}=i_{l} .
$$

It is easy to see that the inequality $t^{*} \leqslant t$ is satisfied for the network $D_{d}$ if and only if there exists a non-positive Hamiltonian circuit in the network $D_{d, u}$. To detect the circuit we can apply the direct method for finding a non-positive Hamiltonian circuit in the network $D_{d, v}$ (see [3] or [7]). Unfortunately, the direct method is not efficient in the accepted sense. Murty , [6] has presented another method for examination of the inequallity $t^{*} \leqslant t$ which also is inefficient.

3. Computational experience. The algorithm was tested on the ODRA 1204 computer, and the computation time was found to depend upon a partition of $-t$ into $t_{1}, t_{2}, \ldots, t_{n}$ and very little upon values of the lower and upper bounds to the optimal solution $t^{*}$. Also, the algorithm was compared with Netter's algorithm.

Two different ways of the partition of $-t$ were tested. According to Netter's suggestion, the first was formed from an $n$-tuple (different for different $t$ ) $t_{1}^{\prime}, t_{2}^{\prime}, \ldots, t_{n}^{\prime}$ of a sequence of uniformly distributed random numbers and

$$
t_{i}=\frac{-t_{i}^{\prime} t}{\sum_{j=1}^{n} t_{j}^{\prime}}
$$


and in the second a generic element $t_{i}$ was in the direct proportion to

$$
-\sum_{j=1, j \neq i}^{n} \frac{d_{i j}}{n-1} .
$$

The times (in sec.) of computations by the algorithms for some problems are shown in Table 1.

TABLE 1

\begin{tabular}{|c|c|c|c|c|}
\hline \multirow{3}{*}{$n$} & \multicolumn{2}{|c|}{ Netter's algorithm } & \multirow{3}{*}{$\begin{array}{c}\begin{array}{c}\text { The bisection } \\
\text { method }\end{array} \\
\begin{array}{c}\text { the second } \\
\text { partition of }-t\end{array}\end{array}$} & \multirow{3}{*}{ Problem source } \\
\hline & \multirow{2}{*}{$\begin{array}{l}\text { the first par- } \\
\text { tition of }-t\end{array}$} & \multirow{2}{*}{$\begin{array}{l}\text { the second } \\
\text { partition } \\
\text { of }-t\end{array}$} & & \\
\hline & & & & \\
\hline 10 & 32 & 23 & 17 & {$[5]$} \\
\hline 10 & 457 & 10 & 11 & $\begin{array}{l}\text { Problem obtained } \\
\text { from the previous } \\
\text { one by symmetriza- } \\
\text { tion of the matrix } D . \\
{\left[\begin{array}{l}{[2]}\end{array}\right.}\end{array}$ \\
\hline
\end{tabular}

Computational time of the new algorithm has been considerably saved due to the new method of generating $t$ and to the partition of it. The reason of the latter is that the second way of partitioning takes values of matrix elements into consideration more than the first one.

The time of examination of the inequality $t^{*} \leqslant t$ for both algorithms was in the inverse proportion to $\left|t-t^{*}\right|$.

\section{References}

[1] N. Christ ofides, Bounds for the traveling-salesman problem, Opns. Res. 20 (1972), p. 1044-1056. Errata, ibidem 22 (1974), p. 1121.

[2] G. B. Dantzig, D. R. Fulkerson and S. M. Johnson, On a linear-programming combinatorial approach to the traveling-salesman problem, ibidem 7 (1959), p. 58-66.

[3] M. Florian and P. Robert, A directed search method to locate megative cycles in a graph, Management Sci. 17 (1971), p. 307-310.

[4] R. M. Karp, Reducibility among combinatorial problems, in: Proceedings of the Symposium on the Complexity of Computer Computations (Editors R. E. Miller and J. W. Thatcher), Plenum Press, New York 1972.

[5] E. L. Lawler and D. E. Wood, Branch-and-boumd methods: a survey, Opns. Res. 14 (1966), p. 699-719. 
[6] K. G. Murty, A fundamental problem in linear inequalities with applications to the travelling salesman problem, Math. Programming 2 (1972), p. 269-308.

[7] J. P. Netter, An algorithm to find elementary negative-cost circuits with a given number of arcs - the traveling-salesman problem, Opns. Res. 19 (1971), p. 234-237.

INSTITUTE OF INFORMATICS

UNIVERSITY OF WROCEAW

50-384 WROCEAW

Received on 25. 9. 1976

M. M. SYSLO (Wroclaw)

\section{METODA POLO WIENIA}

DLA ROZ WIAZY WANIA ZAGADNIENIA KOMIWOJAZERA

STRESZCZENIE

W pracy przedstawiono modyfikacje metody Nettera dla rozwiązywania zagadnienia komiwojażera. Zasadniczy krok algorytmu polega na wyznaczaniu kolejnego przybliżenia przez polowienie przedziału zawierającego szukane rozwiązanie. Obie metody zostały porównane na kilku przykładach. Zaproponowana modyfikacja wpłynęła na zmniejszenie czasu obliczeń na maszynie cyfrowej. 